\title{
Tesis aisladas sobre TRHA de la SCJN (2018-2019): procreación y conformación de la familia
}

\author{
Casandra Gabriela Hernández Sánchez*
}

Es evidente los adelantos de la biomedicina en la actualidad, en particular lo concerniente a las Técnicas de Reproducción Humana Asistida (TRHA), en las cuales se incluyen las técnicas de inseminación artificial, la fecundación in vitro y la gestación por sustitución en la modalidad homóloga y heteróloga.

Hoy en día se observa un aumento del uso de estas técnicas, y, de su tratamiento jurídico o legislativo, se contempla la actividad de la Suprema Corte de Justicia de la Nación (SCJN), por ello, el interés del presente texto es, abordar la postura de la SCJN expuesta en las tesis aisladas emitidas en México.

Cabe recordar que, hace más de cuarenta años ocurrió el nacimiento de la primera bebe de probeta de Lesley y John Brown en el año de 1978, fue unos de los hitos relevantes para mostrar el avance de la biomedicina en relación con las TRHA. (Manganaro, C. 2019).

En los últimos años, la sociedad en general se ha enterado de noticias impactantes, sobre este tema en relación con las TRHA, entre las que se pueden mencionar se encuentra el caso del científico chino, el Dr. He Jiankui, quien modificó los embriones de dos gemelas con el objetivo de crearles resistencia al virus de inmunodeficiencia adquirida (VIH) (Holland, Regan \& Wang, 2018), y el caso de los seres procreados a través de la técnica de reemplazo mitocondrial (Salas, 2016).

Aunque México aún no cuenta con una regulación jurídica homogénea para todo su territorio, sí se han presentado y emitido por parte de la Suprema Corte de Justicia de la Nación (SCJN) diversas tesis aisladas que nos brindan algo de luz con relación a las TRHA.

En la última época, se han presentado relevantes aportes por parte de la SCJN, que ya se encuentra en el Semanario Judicial de la Federación (SJF), estos aportes se podrían llegar a considerar hasta vanguardistas en comparación a las regulaciones jurídicas de otros países.

En adelante, se expondrán algunos de las mencionadas Tesis Aisladas (TA) que se han emitido. En el SJF contemplamos la publicación y adhesión al universo jurídico de elementos relacionados con las TRHA, como lo es el presentado en la tesis aislada 2017232 de junio 2018 intitulada: "Derecho a la reproducción asistida. Forma parte del derecho de decidir de manera libre, responsable e informada sobre el número y el esparcimiento de sus hijos, previsto en el artículo $4^{\circ}$ de la Constitución Política de los Estados Unidos Mexicanos", Artículo $4^{\circ}$ :

\footnotetext{
* Licenciada en Derecho por la Facultad de Derecho de la Universidad Veracruzana.
} 


\section{Hernández C. / Tesis aisladas sobre TRHA de la SCJN (2018-2019): procreación y conformación de la familia}

El varón y la mujer son iguales ante la ley. Esta protegerá la organización y el desarrollo de la familia. Toda persona tiene derecho a decidir de manera libre, responsable e informada sobre el número y el espaciamiento de sus hijos (...).

Nos confirma que recurrir a las TRHA está sustentado por el artículo $4^{\circ}$ de la constitución y la Declaración Universal de los Derechos Humanos (DUDH) en el artículo $16^{\circ}$ :

1. Los hombres y las mujeres, a partir de la edad núbil, tienen derecho, sin restricción alguna por motivos de raza, nacionalidad o religión, a casarse y fundar una familia, y disfrutarán de iguales derechos en cuanto al matrimonio, durante el matrimonio y en caso de disolución del matrimonio (...). (Naciones Unidas, 1948)

Por lo cual, la decisión de hacerlo por medio de las TRHA pertenece a la esfera más íntima de la vida privada y familiar de una pareja, es parte de la autonomía de la voluntad de cada persona.

Diversos expertos han opinado que, el derecho y la decisión de recurrir a las TRHA está amparado o contemplado en el artículo $4^{\circ}$ constitucional, por ejemplo, como lo expone Aníbal Guzmán:

La decisión de tener o no un hijo está previsto por la Constitución en el artículo $4^{\circ}$. En este contexto, muchos especialistas sostienen que, si una persona decide tener hijos y no puede hacerlo por medios naturales, se puede alcanzar dicho fin a través de la asistencia médica a la procreación, ya sea invocando el derecho a la salud, en el entendido que la utilización de los recursos que la tecnología ofrece hoy en día tiene un fin terapéutico; o bien como parte de la libertad del individuo, invocando un derecho a la procreación (...). (Guzmán, 2001: 129)

En el año de 2018 se presentó la tesis aislada 2017287, que versa sobre el elemento esencial para establecer la filiación de los nacidos por TRHA: "Voluntad procreacional. Su fundamento deriva del reconocimiento constitucional y convencional del derecho a la identidad de un menor de edad", se menciona: "La voluntad procreacional es uno de los factores determinantes para la constitución del vínculo filial del menor (...)" (SCJN, 2018f: 981).

Actualmente sólo tenemos elementos esenciales para establecer la filiación biológica y legal.

La presente tabla ilustra los elementos que se contemplarían con relación a los 3 tipos de filiación:

\begin{tabular}{|l|l|l|l|}
\hline Filiación & Biológica & Legal & TRHA \\
\hline Elemento & $\begin{array}{l}\text { Coincidencia genética entre } \\
\text { (ADN) del ascendiente y y } \\
\text { descendiente. }\end{array}$ & $\begin{array}{l}\text { Documento, sentencia o } \\
\text { resolución que reconozca la } \\
\text { filiación. }\end{array}$ & $\begin{array}{l}\text { Documentos donde sea } \\
\text { expresada la voluntad } \\
\text { procreacional. }\end{array}$ \\
\hline
\end{tabular}

Tabla de elaboración propia con base a Varsi (2017).

Es de reconocer que aún no contamos en la totalidad del país mexicano con la regulación, separación y elementos esenciales para establecer la filiación de los tres tipos. Por ejemplo, Veracruz aún contempla la separación discriminatoria de hijos nacidos dentro del matrimonio e hijos nacidos fuera del mismo. 


\section{Hernández C. / Tesis aisladas sobre TRHA de la SCJN (2018-2019): procreación y conformación de la familia}

Lo dicho por la SCJN revela y establece que el elemento esencial de la filiación (importante y necesario en el caso de aplicar las TRHA en modalidad heteróloga), recae sobre la voluntad procreacional.

También es de notar que, se toma en consideración y se habla sobre el derecho a la identidad del menor. Ya que como ha mencionado la Comisión Nacional de Derechos Humanos (CNDH) en su tríptico Niñas, niños y adolescentes tienen derecho a la identidad (2018):

El Fondo de las Naciones Unidas para la Infancia (UNICEF) apunta que el derecho a la identidad consiste en el “...reconocimiento jurídico y social de una persona como sujeto de derechos y responsabilidades y a su vez, de su pertenencia a un Estado, un territorio, una sociedad y una familia, condición necesaria para preservar la dignidad individual y colectiva...". (CNDH,2018)

Por ello es relevante tener clara su filiación y que la misma, no sea negada por la persona que en su momento proporcionó su voluntad procreacional.

Con referencia a lo anterior, la tesis aislada 2017231: señala que, a partir de los derechos generados por el derecho a la identidad del menor se generan otros, como lo son el derecho a recibir:

(...) alimentación, educación, salud y sano esparcimiento. Y que en razón a la protección a estos derechos del menor (...) el derecho a la identidad se tiene que adaptar a las circunstancias del caso concreto ya que puede interactuar con otros derechos, como el de protección a la familia o el propio interés superior del menor, todos ellos protegidos por el Estado. (SCJN, 2018b:956)

Como se distingue hasta ahora es importante tener una filiación y en el caso de la generada por las TRHA que sea clara, y si en su momento se proporcionó el elemento esencial «voluntad procreacional», no se pueda impugnar la paternidad o maternidad, esto con el fin de salvaguardar los derechos del menor tanto los principales como los derivados.

La siguiente tesis aislada que se emitió se podría considerar complemento de la tesis aislada 2017232 antes mencionada. Se trata de la tesis aislada 2017286 de junio de 2018, "Voluntad procreacional. Forma en la que debe acreditarse cuando la legislación respectiva no regula la forma en la que deba otorgarse (Código Civil del Distrito Federal aplicable en la Ciudad de México)".

En ésta se señalan algunos elementos de la voluntad procreacional:

Manifestación: Expresa o tácita.

- Este aspecto volitivo debe estar acreditado

- Se puede concluir que la prueba ideal para acreditar la voluntad procreacional, sea el documento donde conste la expresión de los cónyuges, pareja o persona para someterse a esa técnica, expedido incluso previamente al sometimiento de las $\underline{\text { TRHA. }}$

Aunque se habla de la manifestación tácita del consentimiento al expresar la voluntad procreacional de recurrir a las TRHA, ésta presenta el inconveniente en la expresión de ella y afectará en algún momento, al nuevo ser humano, es necesario que exista constancia de la expresión de la voluntad en algún documento, ya sea por el documento firmado en la clínica donde se realizará la técnica, o implementar la medida que han establecido otros 


\section{Hernández C. / Tesis aisladas sobre TRHA de la SCJN (2018-2019): procreación y conformación de la familia}

países, y confirmar su carácter legal ante alguna autoridad competente. Esto con el fin de proteger en su momento, al menor procreado a través de alguna de las técnicas con especial énfasis en la modalidad heteróloga:

(...) es aquella donde se utilizan espermatozoides u óvulos de un donante sin que estos lo hagan con el fin de generar un lazo de filiación con el nuevo ser sino con la intención de ayudar a aquellas personas que no pueden procrear por alguna de las ya expresadas circunstancias (como infertilidad, esterilidad, ser alguien soltero o una pareja del mismo sexo). (León y Hernández, 2019: 116)

Para esta circunstancia se ha emitido la tesis aislada 2017285 "Voluntad procreacional constituye un factor determinante en la filiación del niño o niña que nació bajo un procedimiento de inseminación artificial heteróloga", que expresa:

(...) lo que se debe acreditar es si los cónyuges otorgaron su voluntad para que la mujer fuera inducida bajo ese tratamiento, ya que en caso afirmativo, jurídicamente se tendrá una filiación con el hijo que nazca de dicha técnica de reproducción asistida y, en consecuencia, respecto del padre, surgirá un parentesco igual a aquel que normalmente se adquiere por consanguinidad; así, cuando en el ejercicio de un derecho en su dimensión de pareja, existe consentimiento de ellos para someterse a una inseminación artificial heteróloga, lo que se está dirigiendo es la voluntad consensuada de ambos, para ejercer su derecho a decidir de manera libre, responsable e informada sobre el número y el espaciamiento de sus hijos, ello a pesar de que entre el cónyuge varón y el menor no existan lazos genéticos; a este consentimiento del padre se le conoce como voluntad procreacional, que es el deseo de asumir a un hijo como propio aunque biológicamente no lo sea. (SCJN, 2018d:980)

Todo ello es para proporcionarle al menor sus derechos generados por la persona en la que recae la paternidad, y atender en su momento, al principio del interés superior del menor.

En relación con todo ello, existe la tesis aislada 2017230 "Derecho a la identidad de un menor. Elementos que se deben tomar en cuenta cuando el niño o niña nació por consecuencia de un tratamiento de inseminación artificial heteróloga", que nos proporciona más información respecto al consentimiento, nos dice que este cumple una doble función: respecto de las consecuencias jurídicas que surgen por quienes se someten a esos tratamientos y, en segundo lugar, en relación con el impacto que se produce en los hijos nacidos bajo esas técnicas.

La expresión de la voluntad procreacional genera consentimiento libre e informado para aplicación de la técnica y aceptación de la paternidad o maternidad en dado caso que se produzca el nacimiento del neonato.

Además, se hace alusión a que el derecho a formar una familia puede ser individual o en pareja, claro está que si se encuentran en una relación conyugal o concubinato es necesario el consentimiento de ambas partes, ya que la toma y producto de esa decisión atañe a la esfera en pareja; al mencionar y darle consideración a lo individual abre la puerta para personas solteras que quieren procrear puedan hacerlo y así gozar de su derecho a decidir cómo formar su familia.

En la reciente tesis aislada 2020442 "Comaternidad. Es una figura referida a la doble filiación Materna en uniones familiares homoparentales", se expresa:

Todo tipo de uniones familiares, entre ellas, las homoparentales conformadas por personas del mismo sexo (...) tienen el derecho a formar una familia, y si es su deseo, acceder a la procreación y crianza de 


\section{Hernández C. / Tesis aisladas sobre TRHA de la SCJN (2018-2019): procreación y \\ conformación de la familia}

hijos propios, adoptados, gestados mediante el uso de técnicas de reproducción asistida, o procreados por uno de ellos. (SCJN, 2019a: 1314)

Aporta una definición de lo que se concibe como comaternidad:

Ahora bien, la comaternidad es una figura propia de la unión familiar homoparental constituida por dos mujeres, que se refiere a la doble filiación materna, por virtud de la cual la pareja de mujeres se encarga del cuidado bajo su seno de uno o más hijos, como cualquier otro ejercicio de crianza parental, aun cuando una de ellas o ambas no tengan un vínculo genético con el hijo o hijos. (SCJN, 2019a: 1314)

Hasta aquí podemos notar el avance con relación a la universalización de los derechos humanos, la posibilidad de tener una familia, acceder a los avances biomédicos y brindarles protección a todos los menores sin importar sus orígenes.

Por último, comentó la tesis aislada 2020783 "Derecho a la Reproducción asistida. Lo tienen las parejas de matrimonios homosexuales".

En donde encontramos uno de los avances más significativos, el que todos tienen derecho a gozar de los beneficios del progreso científico y de sus aplicaciones, y condicionarlo sólo a parejas heterosexuales con problemas de infertilidad o esterilidad (León \& Hernández, 2019: 116), se incurre en discriminación ya que al ser parejas del mismo sexo es imposible el procrear, lo que significa y desde luego formar una familia por lo que tienen que recurrir a las TRHA.

La revisión de las anteriores tesis aisladas, nos muestran una parte velada en relación con el derecho, los derechos humanos y las TRHA, aspecto en el cual México tiene la tarea de

- Crear una Ley General para regular las TRHA

- Crear un registro nacional de donantes de células reproductoras, preembriones, aplicaciones de TRHA y tasas de éxito.

- Acreditar comités bioéticos

- Establecer centros encargados de la aplicación de las TRHA y los protocolos que debe seguir.

- Adaptar su regulación civil con relación a los 3 tipos de filiación

- Modificar su Ley General de Salud

- Tomar en consideración las recomendaciones y resoluciones del consejo de Europa, el proyecto de Convenio de Bioética y las iniciativas de la UNESCO, y la resolución de la Corte Interamericana de Derechos Humanos, así como los instrumentos internacionales que velaran por los DDHH que intervienen antes, durante y después de una TRHA. (León y Hernández, 2019: 124)

El ejercicio de legislar las TRHA, es posible desde la perspectiva del derecho comparado y atendiendo recomendaciones de , que puede tomar de países como Francia, España, Suecia, Dinamarca, Noruega, Alemania e Inglaterra, y en Latinoamérica de Argentina y Uruguay, todos ellos le aportarán pautas esenciales sobre lo principal a regular y para quiénes, de los nuevos avances biomédicos y más, pero todo con el respeto de los derechos humanos de los implicados y su debida proyección a futuro en caso del nacimiento del nuevo ser salvaguardar su interés superior. 
Sin duda, rescatamos que se deben crear instrumentos legislativos en cuanto se trate de la procuración de nuevos seres vivos, y no dejarnos impresionar aletargando al debate o procrastinando su protección jurídica. 


\section{Fuentes de consulta}

Asamblea General de la Organización de las Naciones Unidas. (1948). Declaración Universal de los Derechos Humanos. Resolución 217 A (III). 10 de diciembre 1948.

CNDH. (2018). Niñas, niños y adolescentes tienen derecho a la identidad. Recuperado de https://www.cndh.org.mx/sites/default/files/doc/Programas/Ninez_familia/Materi al/cuadri-identidad-ninas-ninos.pdf

Constitución Política de los Estados Unidos Mexicanos. Recuperado de https://www.scjn.gob.mx/constitucion-politica-de-los-estados-unidos-mexicanos

Guzmán, A. (2001). Inseminación artificial y fecundación in vitro humanas. Un nuevo modo de filiación. Xalapa, Ver. México: Universidad Veracruzana.

Holland, O., Regan, H. \& Wang, S. (28 de noviembre de 2018). El científico chino que dice que modificó dos embriones para resistir el VIH defiende su trabajo y dice que habría un tercer bebé. CNN. Recuperado de https://cnnespanol.cnn.com/2018/11/28/elcientifico-chino-que-dice-que-modifico-dos-embriones-para-resistir-el-vihdefiende-su-trabajo-y-dice-que-habria-un-tercer-bebe/

León López, R. M. y Hernández Sánchez, C. G. (2019). El avance en la regulación de las técnicas de reproducción humana asistida. Letras Jurídicas. Revista multidisciplinar del CEDEGS, Universidad Veracruzana: México.

Manganaro, C. (2019). Louise Brown, en Encyclopaedia Britannica, inc. July 21, 2019. Recuperado de https://www.britannica.com/biography/Louise-Brown

Salas, J. (05 de octubre de 2016). Nace un bebé con la nueva técnica de 'tres padres genéticos'. El país. Recuperado de https://elpais.com/elpais/2016/09/27/ciencia/1474989059_678680.html

Suprema Corte de Justicia de la Nación (2018b). Primera Sala. Tesis Aislada 1ạ. LXXV/2018, Gaceta del Semanario Judicial de la Federación. 10a época, registro 2017231, t. II, libro 55, 22 junio 2018.

Suprema Corte de Justicia de la Nación (2018c). Primera Sala. Tesis Aislada 1ạ. LXXVI/2018, Gaceta del Semanario Judicial de la Federación10a época, registro 2017232, t. II, libro 55, 22 junio 2018. 


\section{Hernández C. / Tesis aisladas sobre TRHA de la SCJN (2018-2019): procreación y}

conformación de la familia

Suprema Corte de Justicia de la Nación (2018d). Primera Sala. Tesis Aislada 1á. LXXVIII/2018, Gaceta del Semanario Judicial de la Federación. 10a época, registro 2017285, t. II, libro 55, 22 junio 2018.

Suprema Corte de Justicia de la Nación (2018e). Primera Sala. Tesis Aislada 1ạ. LXXX/2018, Gaceta del Semanario Judicial de la Federación. 10a época, registro 2017286, t. II, libro 55, 22 junio 2018.

Suprema Corte de Justicia de la Nación (2018f). Primera Sala. Tesis Aislada 1ạ. LXXIX/2018, Gaceta del Semanario Judicial de la Federación. 10a época, registro 2017287, t. II, libro 55, 22 junio 2018.

Suprema Corte de Justicia de la Nación (2019a). Primera Sala. Tesis Aislada 1a. LXV/2019, Gaceta del Semanario Judicial de la Federación. 10a época, registro 2020442, t. II, libro 69, 22 agosto 2019.

Suprema Corte de Justicia de la Nación (2019b). Primera Sala. Tesis Aislada 1á. LXXXVII/2019, Gaceta del Semanario Judicial de la Federación. 10a época, registro 2020783, t. II, libro 71, 11 octubre 2019.

Suprema Corte de Justicia de la Nación. (2018a). Primera Sala. Tesis Aislada 1a . LXXVII/2018, Gaceta del Semanario Judicial de la Federación. 10a época, registro 2017230, t. II, libro 55, 22 junio 2018.

Varsi, E. (2017). Determinación de la filiación en la procreación asistida. Revista IUS, 11(39) Recuperado

de http://www.scielo.org.mx/scielo.php?script=sci_arttext\&pid=S1870$21472017000100006 \& \operatorname{lng}=e s \&$ tIng=es 